\title{
Drugs for Multiple Sclerosis Activate Natural Killer Cells: Do They Protect Against COVID-19 Infection?
}

This article was published in the following Dove Press journal: Infection and Drug Resistance

\begin{abstract}
Mena Al-Ani ${ }^{1, *}$
Noha Mousaad Elemam (D) ${ }^{1, *}$ Jennifer Elisabeth Hundt ${ }^{2}$ Azzam A Maghazachi (D)

'Department of Clinical Sciences, College of Medicine and the Immuno-Oncology Group, Sharjah Institute for Medical Research, University of Sharjah, Sharjah 27272, United Arab Emirates; ${ }^{2}$ Lübeck Institute for Experimental Dermatology, University of Lübeck, Lübeck, Germany
\end{abstract}

*These authors contributed equally to this work
Correspondence: Azzam A Maghazachi Department of Clinical Sciences, College of Medicine and Sharjah Institute for Medical Research, University of Sharjah, Sharjah 27272, United Arab Emirates Email amagazachi@sharjah.ac.ae

\begin{abstract}
COVID-19 infection caused by the newly discovered coronavirus severe acute respiratory distress syndrome virus-19 (SARS-CoV-2) has become a pandemic issue across the globe. There are currently many investigations taking place to look for specific, safe and potent anti-viral agents. Upon transmission and entry into the human body, SARS-CoV-2 triggers multiple immune players to be involved in the fight against the viral infection. Amongst these immune cells are NK cells that possess robust antiviral activity, and which do not require prior sensitization. However, NK cell count and activity were found to be impaired in COVID-19 patients and hence, could become a potential therapeutic target for COVID-19. Several drugs, including glatiramer acetate (GA), vitamin $\mathrm{D}_{3}$, dimethyl fumarate (DMF), monomethyl fumarate (MMF), natalizumab, ocrelizumab, and IFN- $\beta$, among others have been previously described to increase the biological activities of NK cells especially their cytolytic potential as reported by upregulation of $\mathrm{CD} 107 \mathrm{a}$, and the release of perforin and granzymes. In this review, we propose that such drugs could potentially restore NK cell activity allowing individuals to be more protective against COVID-19 infection and its complications.
\end{abstract}

Keywords: NK cells, multiple sclerosis, COVID-19

\section{Introduction}

Coronaviruses (CoVs) are large positive stranded enveloped RNA viruses that cause enteric and mild or severe respiratory diseases in animals and humans. ${ }^{1}$ Coronaviruses are named based on their morphology as spherical virions with a core shell and surface projections, that are classified into four subfamilies, namely alpha, beta, gamma and delta. SARS-CoV-2 belongs to the beta-coronaviruses and is closely related to the severe acute respiratory distress syndrome virus (SARS$\mathrm{CoV}$ ), that emerged earlier this century. ${ }^{2-4}$ Recently, COVID-19 infection was reported to be caused by SARS-CoV-2 in Wuhan, China. ${ }^{5}$ Additionally, it was associated with mortality in a ratio of the patients similar to other previously reported CoVs. ${ }^{6}$ COVID-19 could be transmitted through huge droplets caused by coughing and/or sneezing. ${ }^{7}$

Similar to SARS-CoV, SARS-CoV-2 uses a unique receptor for cell entry, which is angiotensin converting enzyme 2 (ACE2).$^{8-11}$ The clinical symptoms could vary from fatigue, fever, headache, dyspnea, nasal congestion and cough, as well as gastrointestinal symptoms including nausea, vomiting, diarrhea and abdominal pain. $^{2,12}$ In severe cases, these symptoms are aggravated to shortness of breath 
and pneumonia that could lead to acute respiratory distress syndrome (ARDS) and other complications. ${ }^{13,14}$ A study performed on hospitalized patients with SARS-CoV-2 associated pneumonia reported that the most common symptoms were fever $(83 \%)$ and cough $(82 \%)$, followed by shortness of breath (31\%). ${ }^{15}$ As part of the inflammatory process, markers such as C-reactive protein, erythrocyte sedimentation rate and proinflammatory cytokines are elevated. ${ }^{13}$ The extremely high concentration of cytokines "cytokine storm" was recorded in plasma of severe cases of COVID-19 patients and was associated with disease severity. ${ }^{16}$ The inflammatory cytokines include granulocyte colony stimulating factor (G-CSF), IL-2, IL-7, IL10, TNF $\alpha$ and the chemokines CCL2, CCL3, and CXCL10. ${ }^{16,17}$

Various current therapeutic agents are currently being investigated for treatment of COVID-19. Use of intravenous immunoglobulins has been described to show great efficiency especially in severe and deteriorating patients infected with SARS-CoV-2. ${ }^{18}$ Also, anti-viral agents such as remdesivir have been examined as potential candidates for COVID-19 therapy. Hydroxychloroquine and chloroquine have been suggested to inhibit viral replication and activity. ${ }^{19}$ Since antiretroviral drugs previously showed efficacy against SARS-CoV, lopinavir/ritonavir may have potential therapy in COVID-19 patients. ${ }^{20,21}$ For instance, the JAK inhibitor baricitinib that is used for treating rheumatoid arthritis patients was suggested to control viral replication and treatment of COVID-19 infection. ${ }^{22,23}$ Because many of the drugs used currently in COVID-19 treatment were primarily used for the treatment of autoimmune diseases, it was of interest to see if the immunomodulatory agents used in multiple sclerosis therapy could be utilized for treating of COVID-19 through activation of natural killer cells.

\section{Natural Killer Cells}

Natural killer (NK) cells are innate immune cells that are programmed to protect humans from viral infections and cancer. $^{24-26}$ The main cytotoxic function of NK cells is through apoptotic induction and lysis of virally infected cells via perforin and granzymes. Also, NK cells are able to secrete immunoregulatory cytokines such as IFN- $\gamma$ and TNF- $\alpha$, that regulate the immune responses. ${ }^{27,28}$ IFN- $\gamma$ and TNF- $\alpha$ are known to play a critical role in the control of viral infections, by indirect stimulation of the cytolytic function of NK cells. ${ }^{29}$ Further, they were reported to act as immune-defensive mediators that activate and recruit other inflammatory immune cells. ${ }^{30}$ Also, these cytokines were reported to influence the innate and adaptive immune cells. ${ }^{31,32}$

NK cells are $\mathrm{CD}^{-}$and further divided into two main subsets based on the expression of certain markers. Accordingly, NK cells that express CD56 but not CD16, known as CD56 ${ }^{\text {bright }}$, represent about $10-20 \%$ of total NK cells in the blood, whereas those that express CD16 and low CD56, known as CD56 $6^{\mathrm{dim}}$, represent about $80-90 \%$ of total circulating NK cells. CD56 ${ }^{\mathrm{dim}}$ cells have been shown to predominantly mediate cytotoxicity, whereas CD56 ${ }^{\text {bright }}$ cells appear to principally secrete cytokines, ${ }^{33}$ albeit both susbsets acquire both activities upon activation. ${ }^{34} \mathrm{NK}$ effector function is controlled by a complex network of signals, which interact with membrane-expressed inhibitory and activating receptors. ${ }^{35}$

The inhibitory receptors maintain the immunological homeostasis by binding to the major histocompatibility complex (MHC) expressed on healthy cells. Downregulation of MHC class I or loss of its expression during viral infection lifts the inhibitory signal imposed on NK cells, resulting in their activation. These inhibitory receptors include C-type lectin-like receptors such as NKG2A, and the killer-cell immunoglobulin-like receptors (KIRs). Activation receptors recognize stressed ligands on virally infected and tumor cells. These receptors include NKG2D, and the natural cytotoxicity receptors (NCRs) such as NKp30, NKp44 and NKp46, among others. ${ }^{36-40} \mathrm{NK}$ cell activity depends on the balance between activation and inhibitory signals; when the threshold of the activation signal exceeds the inhibitory ones, then NK cells can perform their function, whether cytotoxicity or cytokine secretion, in order to eliminate virally infected cells. ${ }^{33,37}$

It is worth mentioning that there are differences among human and murine NK cells. For instance, human NK cells express CD56 and can be classified into bright and dim subsets whereas murine NK cells do not express CD56 but instead express CD27. ${ }^{41}$ Additionally, human NK cells express KIR, but murine NK cells express Ly49 receptors which are not found in humans. ${ }^{42}$

\section{Search Strategy}

Articles were searched in the literature using the keywords: multiple sclerosis, experimental autoimmune encephalomyelitis, drugs, COVID-19, and natural killer cells. These articles were checked thoroughly, and any unnecessary or irrelevant information was removed. Subsequently, included articles were used to search for a possible link 
between natural killer cells, COVID-19 and the action of various drugs. Research articles and reviews were included from those published in the past 15 years from papers using the keywords "COVID-19 and multiple sclerosis", "multiple sclerosis and natural killer cells", "drugs and multiple sclerosis and natural killer cells", or "COVID19 and natural killer cells".

\section{Role of NK Cells in Viral Infection}

NK cells possess distinct ability to recognize and fight viruses by performing cytolytic activity against infected cells and by producing the antiviral cytokines. ${ }^{43,44}$ IFN- $\gamma$ affects viral replication and entry into host cells, as well as recruiting and activating other effector leukocytes, including cytotoxic $\mathrm{T}$ lymphocytes and $\mathrm{CD}^{+} \mathrm{T}$ helper type 1 cells. ${ }^{45} \mathrm{NK}$ cells are crucial in the innate immune response against various viruses including human immunodeficiency virus, herpesvirus, poxvirus, papillomavirus, hepatitis B, hepatitis C, influenza and cytomegalovirus. ${ }^{24,25,46-50}$ The effects of NK cells on several viral infections have been previously described and discussed in other papers. ${ }^{51-55}$ This article will focus on the possibility that activated NK cells might protect against COVID-19 infection.

\section{Status of NK Cells During COVID-I 9 Infection}

Upon entry of microbial particles into the respiratory mucosa and infection of lung resident cells, a series of immune reactions take place corroborated with a cytokine storm within the body, resulting in the impairment of the coagulation system, and the generation of disseminated intravascular coagulation leading to septic shock and multi-organ disorder. ${ }^{56}$ Lymphopenia has been reported to be associated with COVID-19 infection, indicating that SARS-CoV-2 destroys numerous immune cells and hinders the cellular immune responses. This suggests that SARS-CoV-2 might primarily act on monocytes and $\mathrm{T}$ cells, similar to the previously reported SARS-CoV. ${ }^{57}$

The most crucial antiviral players are the adaptive immune system members cytotoxic $\mathrm{CD}^{+} \mathrm{T}$ lymphocytes and innate immune NK cells. In persistent/chronic viral infections, the functional activity of NK cells is impaired and worn out. ${ }^{58}$ However, the status of NK cells in patients infected with SARS-CoV-2 is still under investigation. A recent study reported that there is a marked decrease in the total number of $\mathrm{NK}$ and $\mathrm{CD}^{+} \mathrm{T}$ lymphocytes in patients with COVID-19 infection. ${ }^{59}$ Furthermore, this decrease in NK cell count was only observed in the severe COVID-19 patients in comparison to the mild cases or the healthy controls. ${ }^{59}$ Additionally, there was an increase in the expression of the inhibitory receptor $\mathrm{NKG} 2 \mathrm{~A}$ on $\mathrm{NK}$ cells of COVID-19 patients, that was decreased after therapy with lopinavir/ritonavir, chloroquine phosphate, interferon, or antibiotic. ${ }^{59}$ Hence, downregulation of NKG2A expression may be correlated with disease amelioration and therapy in COVID-19 patients. Furthermore, NK cells of COVID-19 patients displayed impaired functional activity as observed by low expression of CD107a and granzyme B, the effector molecules of cytotoxicity. ${ }^{59}$ For cytokine secretion, IFN- $\gamma$ was lower in COVID-19 patients. This was further supported by other studies where interferon responses are highly impaired in patients with severe COVID-19 infection, as indicated by low levels of interferon and interferon stimulating genes, despite the elevation in the inflammatory responses and cytokines such as TNF and IL- $6 .{ }^{60}$ IFN- $\gamma$ is known to have antiviral effects, and is efficient against coronaviruses, as well as inhibiting SARS-CoV replication in vitro. ${ }^{61}$ In support of this, IFN- $\gamma$ is among the highly released cytokines during COVID-19 infection. ${ }^{62}$

The impairment of immune system in COVID-19 was further supported by another study where a significant decrease in the total number of lymphocytes in COVID19 pneumonia patients was observed. ${ }^{63}$ Furthermore, NK cells were found to be significantly lower in COVID-19 pneumonia patients. This alteration in the immune population and specifically of NK cells was previously reported in other pneumonia studies of the same virus family, ie, MERS-CoV and SARS-CoV. ${ }^{64,65}$ Upon classification of cases into mild and severe ones, NK cells were found to be slightly lower in the severe cases, but this change was not statistically significant. Additionally, the percentage of NK cells was not restored after 1 week of treating pneumonia. These observations provide an insight into NK cell exhaustion during COVID-19 infection, and highlighting their vital roles in fighting against coronaviruses such as SARS-CoV-2. ${ }^{59}$

As indicated, several reports showed that NK cells are impaired in coronavirus infections. For instance, a study by the National Research Project for SARS described a decrease in the total number of NK cells as well as in NK cells and other cells expressing KIR2DL2/L2 (CD158b) in SARS-CoV patients when compared to healthy controls and individuals infected with the bacteria Mycoplasma pneumoniae. ${ }^{66}$ This decline in NK cell 
numbers was positively correlated with disease severity, as severe cases showed a larger decline in the total NK and $\mathrm{CD}_{158 \mathrm{~b}^{+}} \mathrm{NK}$ cells compared to mild cases. A possible explanation for the decline in NK cells could be that these cells migrate from the circulation into the sites of infection such as the lungs. Alternatively, NK cell death could occur directly by SARS-CoV and SARS-CoV-2 as an immune evasion strategy. Hence, higher viral load might cause more NK cells to be destroyed resulting in more severe clinical symptoms. ${ }^{66}$

\section{NK Cells: Potential Therapeutic Target in COVID-I 9}

Since NK cells are key anti-viral players, they could be utilized as a therapeutic tool in fighting COVID-19. A study by Osman et al reported that NK cells are not only important for the viral clearance of SARS-CoV-2 but they also limit the severe cytokine storm associated with COVID-19. ${ }^{67}$

CYNK-001 cells are allogeneic, off-the-shelf, cryopreserved natural killer cell therapy, that are derived from placental hematopoietic stem cells. These cells are currently in clinical trials for treatment of several types of cancer including leukemia and multiple myeloma. CYNK001 cells possess NK cell activities as demonstrated by the expression of activating receptors NKG2D, DNAM-1 and the NCRs which bind stress ligands and viral antigens on infected cells. The company "Celularity" has initiated a clinical trial to use CYNK-001 cells in a Phase $1 / 2$ clinical trials done on 86 patients with COVID-19. ${ }^{68,69}$ The study aimed at administering NK cells to patients with moderate-severe COVID-19 symptoms, thus allowing these killer cells to migrate towards active viral infection sites in order to aid and stimulate other immune cells. Therefore, CYNK-001 could halt the replication and eliminate SARS-CoV-2 which could be of benefit to COVID19 patients.

NK cells have been previously modified genetically to express specific receptors to target cancer cells known as chimeric antigen receptor "CAR" NK cells. ${ }^{70,71}$ CAR-NK cells do not cause cytokine storm unlike CAR-T cells, and are relatively safer. ${ }^{72}$ CAR-NK cells have been suggested to be utilized to fight viral infections such as COVID-19. These CAR-NK cells were derived from human umbilical cord blood expressing the activating receptor NKG2D and the entry receptor ACE2 (NCT04324996). ${ }^{73}$ Consequently, a clinical trial using CAR-NK cells was initiated in early- stage COVID-19 patients. In addition, there is currently an ongoing clinical trial (NCT04280224) by the National Institutes of Health (NIH), with the purpose of evaluating the safety and efficiency of NK Cells in combination with standard therapy for COVID-19 pneumonia patients.

\section{Multiple Sclerosis}

Multiple sclerosis (MS) is an autoimmune-mediated disorder that is likely to affect the central nervous system (CNS) including the brain and spinal cord. ${ }^{74}$ The pathogenesis of this disease is related to the attacks of the myelin sheath that covers the nerve fibers by the immune system, leading to nerve demyelination. ${ }^{75,76}$ These immune cells are activated in the periphery by myelin antigens followed by the extravasation of $\mathrm{CD} 4^{+}, \mathrm{CD} 8^{+}$, $\mathrm{B}$, macrophages and NK cells into the CNS. ${ }^{77,78}$ Upon destruction, the nerve transmission could be impaired partially or completely damaged, affecting the nerval communications across the human body and causing permanent irreversible damage. A hallmark of the immune response in MS is the formation of isolated areas of inflammation called MS lesions, that may appear both in the white matter and in the grey matter of the brain. ${ }^{79}$ The clinical signs and symptoms of MS were previously discussed and reviewed in detail. ${ }^{80}$

There are several forms and types of MS, the most common form is the relapsing-remitting MS (RRMS), where relapses of disease are separated by remission periods without any clinical progression. When the symptoms deteriorate, ie, during relapse phase, there is an active inflammation within the CNS. As the relapse period ends, the severity of symptoms is reduced and a clinical improvement is presented, referred to as remission phase. ${ }^{80,81}$ Other less common subtypes of MS include primary progressive MS (PPMS), affecting 15\% of MS patients, where neurological deterioration is present from the onset of the disease. ${ }^{80,81}$ On the other hand, secondary progressive MS (SPMS) occurs when patients experience episodes of relapse and remission, followed by a steady progression of the disease. Lastly, progressive relapsing MS (PRMS) is a rare type of MS that is diagnosed when the disease progresses gradually with intermittent flare-ups of worsening symptoms without periods of remission. ${ }^{82,83}$ Although there is no cure for multiple sclerosis, the available disease-modifying agents are used in treating MS patients with the aim of shortening acute exacerbations and diminishing recurrence. ${ }^{84,85}$ 


\section{Role of NK Cells in Multiple Sclerosis}

The function of NK cells in MS has is controversial, with protective and pathogenic roles in MS patients and in animal model, the experimental autoimmune encephalomyelitis (EAE). ${ }^{77,78,86-89}$ For instance, blocking the inhibitory receptor $\mathrm{NKG} 2 \mathrm{~A}$ on $\mathrm{NK}$ cells inhibited CNS inflammation and caused remission by NK cell lysis of autoreactive $\mathrm{T}$ cells and microglial cells. ${ }^{90}$ Additionally, NK cells have shown a regulatory role in EAE where they can improve disease status. ${ }^{91-93}$ NK cells possess a key regulatory function by suppression of pathogenic autoreactive T-cells that cause inflammation, hence possibly leading to restoration of the demyelination..$^{77,78,94}$ On the other hand, it was shown that NK cells in MS may contribute to CNS damage. ${ }^{95} \mathrm{NK}$ cells in the cerebrospinal fluid (CSF) release significant amounts of cytokine and chemokines, potentially contributing to the inflammatory process in MS. ${ }^{96}$ It was shown that the NK cell population in the CNS consists mainly of CD56 $6^{\text {bright }} \mathrm{NK}$ cells, which exhibit a higher migratory potential. ${ }^{97,98}$ Further, NK17/NK1 cells, a rare subset of NK cells, are abundant in the CSF of MS patients. ${ }^{99,100}$ These cells secrete IL-17 and IFN- $\gamma$, two highly inflammatory cytokines, which may contribute to exaggerating the inflammatory response in the brain of MS patients. ${ }^{99,100}$ In contrast, NK cells express the inhibitory $\mathrm{NKG} 2 \mathrm{~A}$ receptor which binds $\mathrm{MHC}$ class molecule HLA-E, and that $\mathrm{NKG}_{2} \mathrm{~A}^{+} \mathrm{NK}$ cells reduce CNS inflammation by lysing $\mathrm{T}$ cells and microglial cells, thus improving the EAE disease state. ${ }^{101}$ Previous data showed that active MS lesions and white matter lesions of MS patients have higher expression of HLA-E. ${ }^{102}$

Interestingly, a recent review suggested that NK cells and specifically the CD56 $6^{\text {bright }}$ cells are increased upon treatment with various MS therapies such as interferonbeta, dimethyl fumarate, and fingolimod. ${ }^{103}$ Such increase in $\mathrm{CD}_{5} 6^{\text {bright }} \mathrm{NK}$ cells is associated with immunoregulatory function and could be used as a potential biomarker for treatment response in MS. ${ }^{103}$

\section{Effects of MS Therapy on NK Cell Activity}

Glatiramer acetate (GA, Copaxone) is an approved drug for the treatment of MS, especially the RRMS. ${ }^{104,105}$ It is made up of four amino acids, namely Glutamic acid, Alanine, Lysine and Tyrosine, that are found in myelin. It improves MS symptoms by acting as a copolymer that binds to MHC molecules and competes with myelin antigens for presentation to $\mathrm{T}$ cells. ${ }^{104,106}$ Additionally, GA has been reported to activate in vitro NK cell lysis of autologous and allogeneic human immature and mature monocyte-derived dendritic cells (DCs), ${ }^{107}$ and in MS patients receiving this drug. ${ }^{108}$ This activity of NK cells may result in impeding auto antigen presentation to autoreactive $\mathrm{T}$ cells and consequently, halts inflammation. Another mechanism of the ameliorating effect of GA is the initiation of the anti-inflammatory Th2 immune activity as shown by the release of IL-5 and IL-13 cytokines, ${ }^{109}$ and activation of type 2 monocytes. ${ }^{110}$ We previously reported that the activating NK cell receptors NKp30, NKp44, NKp46 and NKG2D were elevated, whereas the expression of CD158 receptor was reduced during a oneyear follow-up of RRMS patients receiving GA therapy. ${ }^{108}$ Based on GA robust activity enhancing NK cell activity in vitro, in EAE mice and in MS patients receiving this drug, we would like to advocate its use in treating COVID-19 patients.

Fumaric acid esters are a group of simple structured compounds that have been used in the treatment of inflammatory disorders including psoriasis and multiple sclerosis. $^{111}$ Dimethyl fumarate (DMF), known as Tecfidera, was approved for the treatment of RRMS. ${ }^{85,112}$ However, the exact mechanism of action remains unknown. DMF and its metabolite monomethyl fumarate (MMF) enhance the expression of Nuclear-factor (erythroid-derived 2)-related factor-2 (Nrf2), thus showing protection of potential oligodendrocytes, glial cells, and neurons. ${ }^{112,113}$ Recent data reported a significant increase in NK cell count during two years of DMF treatment, highlighting a crucial regulatory effect of NK cells on immune system modulation in MS. ${ }^{114}$

Similar to GA and DMF, monomethyl fumarate (MMF) has anti-inflammatory properties due to its ability to promote a Th2 immune response as shown by an enhanced secretion of IL-4 and IL-5. ${ }^{115}$ Another common feature with GA, MMF decreased the EAE clinical score along with an enhanced NK cell lysis of dendritic cells. ${ }^{116}$ Additionally, MMF potentiates the killing activity of $\mathrm{NK}$ cells of several cancer cell lines including K562, RAJI and HCT-116. ${ }^{117,118}$ This occurs with a concomitant increase in the expression of the activating receptor NKp46, the degranulation marker CD107a and the cytolytic granzyme B. ${ }^{118}$ In addition, CCR10 chemokine receptor was upregulated on $\mathrm{NK}$ cells using GA, DMF or MMF, ${ }^{119}$ leading to a higher migration of NK cells towards the chemokine 
ligands for CCR10, which include CCl27 and CCL28. ${ }^{117}$ The latter chemokine is important for protection against HIV-1 infection, ${ }^{120}$ which could plausibly be similar during COVID-19 infection. Intriguingly, both DMF and MMF exert anti-inflammatory activities, hypermethylating gasdermin $\mathrm{D}$ and consequently, inhibiting pyroptosis and IL-1 $\beta$ secretion from NK cells. ${ }^{121}$

It has been reported that there is an increase of CD56 ${ }^{\text {bright }} \mathrm{NK}$ cells in MS patients treated with DMF, which is correlated with a decrease in the number of cytotoxic T cells "CTLs". ${ }^{122}$ In fact, CD56 ${ }^{\text {bright }}$ NK cell enrichment takes place after six months of DMF treatment. ${ }^{123}$ The relationship between increased NK cell number and activity and reduced CTLs is not clear. However, it might be plausible that such a process might give the opportunity for NK cells to perform a more robust function against virally infected cells in the absence of other cell types that could impede NK cell activity, although such hypothesis has not been examined yet.

The anti-tumor effects exerted by NK cells after pretreatment with DMF or MMF, along with the ability of these drugs to recruit NK cells towards the sites of inflammation, strongly suggest that they can be used to potentiate NK cells against COVID-19-infected cells. The fact that DMF or MMF reduced or completely inhibited inflammation also supports using these molecules in such therapy. It is plausible that DMF and MMF not only activate NK cells to fight COVID-19 infected cells, but they may also help in reducing the cytokine burst, which is the major cause of death in COVID-19 patients.

Another risk factor of MS is vitamin $\mathrm{D}_{3}$ deficiency, ${ }^{124}$ where it was observed that its administration prevented EAE development, ${ }^{125,126}$ and caused less relapses in MS patients. ${ }^{127}$ On the other hand, another study by Hupperts et al indicated that vitamin $\mathrm{D}_{3}$ could lead to a reduction in the development of new MS lesions. ${ }^{128}$ It was also reported that MS patients may have increased vitamin $D_{3}$ binding proteins, suggesting that such a binding protein may halt the activity of vitamin $\mathrm{D}_{3}$ in MS patients. ${ }^{129}$ Similar to other drugs used to treat MS patients, it was reported that vitamin $\mathrm{D}_{3}$ and its derivative calcipotriol enhance NK cell activation and in vitro cytolysis of DCs, thus reducing antigen presentation to $\mathrm{CD}^{+} \mathrm{T}$ cells. ${ }^{130}$ Vitamin $\mathrm{D}_{3}$ also shifts the immune system towards $\mathrm{Th} 2$ immune response, ${ }^{131}$ along with an improvement in the function of Treg cells in relapsing remitting MS patients. ${ }^{132}$
The drug FTY720 "fingolimod; 2-amino-2-(2-[4-octylphenyl]ethyl)-1,3-propanediol)" is an immunosuppressive drug derived from myriocin, a fungal metabolite that is similar to sphingosine. This drug has been tried on RRMS patients where it showed a reduction in MS lesions and relapse rates. ${ }^{133,134}$ Regarding its activity on NK cells, FTY720 upregulated the expression of the activating receptors NKp30, NKp44 and NKG2D on NK cells. Moreover, FTY720 enhanced IL-2-activated NK cell lysis of immature and mature DCs, impeding autoreactive T cell activation, ${ }^{130}$ in addition to activating NK cell lysis of tumor target cells. ${ }^{135}$ It is worth mentioning that FTY720 is currently under clinical trial to assess the efficacy of fingolimod for treatment of COVID-19 (NCT04280588). Although not yet examined, however, it is highly plausible that FTY720 might induce robust NK cell activity in COVID-19 patients. This is based on FTY720 effects on NK cells described in vitro. ${ }^{130}$

One of the known and established therapeutic agents for MS is interferon- $\beta$ (IFN- $\beta$ ). IFN- $\beta$ was found to alter the phenotype and activation of NK cells. For instance, IFN- $\beta$ upregulated MHC class I expression, thus increasing the inhibitory signals and reducing NK cell cytotoxicity. Additionally, IFN- $\beta$ expands the CD $56^{\text {bright }}$ NK cells in the peripheral blood of MS treated patients. ${ }^{136}$ This was accompanied by an alteration in their phenotype as reported by a decrease in the expression of the inhibitory LILRB1 receptor and an increase of NKG2A receptor. ${ }^{137}$

Natalizumab (Tysabri), a drug for MS patients, is an adhesion molecule inhibitor, that blocks $\alpha 4 \beta 1$-integrin, a receptor which is crucial in the migration and recruitment of inflammatory activated immune cells into the CNS. $^{88}$ Upon natalizumab treatment, there was a reported increase in circulating NK cells, ${ }^{138}$ as possible reduction in their migration capacity into the CNS.

A current drug for MS patients is ocrelizumab, an antiCD20 monoclonal antibody that causes B cell depletion similar to rituximab. A possible mechanism of action could be upon binding to CD20, ocrelizumab triggers antibody-dependent cell-mediated cytotoxicity (ADCC) and apoptosis through NK cells. ${ }^{139}$ Therefore, it is of interest to use natalizumab or ocrelizumab for treating COVID-19 patients where the mechanism of ocrelizumab in COVID19 patients could be similar to its effect in lymphoma patients, ie, stimulates NK cell ADCC activity.

\section{Concluding Remarks}

In the previous sections, we highlighted the important role of NK cells in fighting viral infections especially the 
coronavirus family. Recent studies have shown that NK cells are impaired in number and activity during COVID19 infection. Being important anti-viral effectors, NK cells could be vital tools for therapy of COVID-19 patients. Hence, robust activation of NK cells may be an important factor for subsiding the severity of the disease. We hypothesize that drugs used to treat MS patients such as $\mathrm{GA}$, vitamin $\mathrm{D}_{3}$, DMF, MMF, natalizumab or ocrelizumab, among others could be utilized as tools for boosting NK cell activation (Figure 1). Furthermore, studies investigating whether MS patients undertaking the above medications are less susceptible and more protected from severe complications of COVID-19 infection should be conducted. This strategy should form the basis for new therapeutic approach as the current working medications for treatment of COVID-19 include drugs that have been used

\section{Multiple Sclerosis Drugs}

\section{Interferon- $\beta$}

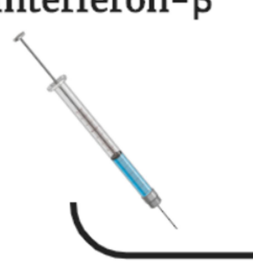

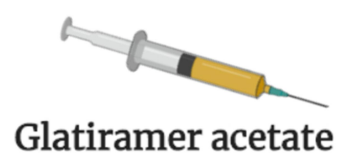

Ocrelizumab

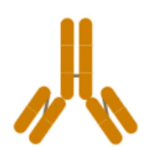

Dimethyl fumarate

(DMF)<smiles>COC(=O)C=CC(=O)OC</smiles>
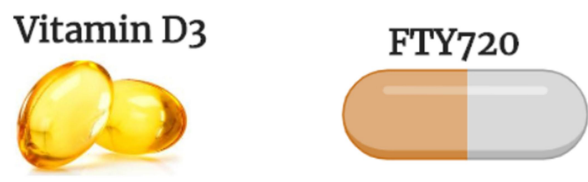

\section{Activation of NK Cells}

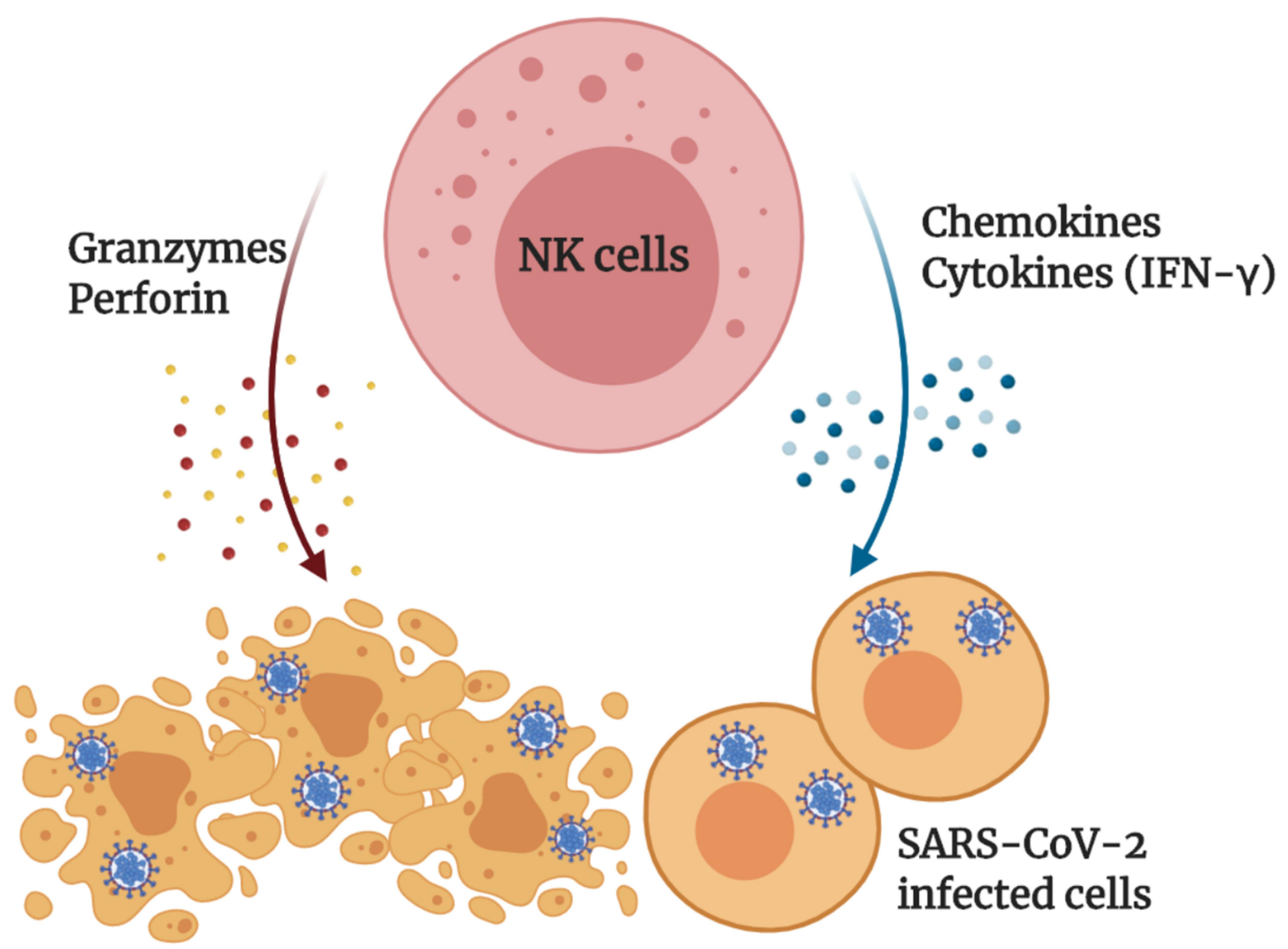

Figure I Multiple sclerosis drugs as potential therapeutic agents for COVID-19. Drugs such as glatiramer acetate, vitamin $D_{3}$, dimethyl fumarate, monomethyl fumarate, interferon- $\beta$, natalizumab or ocrelizumab, boost NK cell activity that could potentially eradicate SARS-CoV-2 virally infected cells. 
for treatment of other autoimmune diseases such as rheumatoid arthritis and systemic lupus erythematosus.

\section{Abbreviations}

ACE2, angiotensin converting enzyme 2; CCL, CC chemokine ligand; CNS, central nervous system; CoVs, coronaviruses; CSF, cerebrospinal fluid; CXCL, CXC chemokine ligand; DCs, dendritic cells; DMF, dimethyl fumarate; EAE, experiment autoimmune encephalitis; FTY720, fingolimod; 2-amino-2-(2-[4-octylphenyl] ethyl)-1,3-propanediol); G-CSF, granulocyte-colony stimulating factor; GA, glatiramer acetate; IFN- $\gamma$, interferon gamma; KIRs, killer immunoglobulin-like receptors; MERS-Cov, Middle East respiratory syndrome-related coronavirus; MHC, major histocompatibility complex; MMF, monomethyl fumarate; MS, multiple sclerosis; NCR, natural cytotoxicity receptors; NK cells, natural killer cells; Nrf2, nuclear-factor (erythroid-derived 2)related factor-2; PPMS, primary progressive multiple sclerosis; PRMS, progressive relapsing multiple sclerosis; RRMS, relapsing-remitting multiple sclerosis; SARSCoV-2/COVID-19, severe acute respiratory distress syndrome virus-19; SPMS, secondary progressive multiple sclerosis; $\mathrm{T}$ regs, regulatory $\mathrm{T}$ cells; TNF, tumor necrosis factor.

\section{Author Contributions}

Al-Ani M., Elemam N.M, Hundt J.E and Maghazachi A. A. contributed significantly to the conception, study design, execution, acquisition of data, analysis and interpretation. Al-Ani M., Elemam N.M, Hundt J.E and Maghazachi A.A. wrote and/or revised the article. All authors agreed on the journal to which the article will be submitted, and reviewed all versions of the article before submission, during revision, and the final version. All authors agree to take responsibility and be accountable for the contents of the article.

\section{Funding}

The work in the authors' laboratory is supported by grants from Terry Fox Foundation grant number MISC051.

\section{Disclosure}

The authors declare that the work was conducted in the absence of any commercial or financial relationships that could be construed as a potential conflict of interest. The authors report no conflicts of interest for this work.

\section{References}

1. Rota PA, Oberste MS, Monroe SS, et al. Characterization of a novel coronavirus associated with severe acute respiratory syndrome. Science. 2003;300(5264):1394-1399. doi:10.1126/ science. 1085952

2. Velavan TP, Meyer CG. The COVID-19 epidemic. Trop Med Int Health. 2020;25(3):278-280. doi:10.1111/tmi.13383

3. Zhou P, Yang XL, Wang XG, et al. A pneumonia outbreak associated with a new coronavirus of probable bat origin. Nature. 2020;579 (7798):270-273. doi:10.1038/s41586-020-2012-7

4. GISAID Global Initiative on Sharing All Influenza Data. Phylogeny of SARS-like betacoronaviruses including novelcoronavirus (nCoV). Available from: https://nextstrain.org/groups/ blab/sars-like-cov.

5. Wang C, Horby PW, Hayden FG, Gao GF. A novel coronavirus outbreak of global health concern. Lancet. 2020;395 (10223):470-473. doi:10.1016/S0140-6736(20)30185-9

6. Manocha S, Walley KR, Russell JA. Severe acute respiratory distress syndrome (SARS): a critical care perspective. Crit Care Med. 2003;31 (11):2684-2692. doi:10.1097/01.CCM.0000091929.51288.5F

7. Rothe C, Schunk M, Sothmann P, et al. Transmission of 2019-nCoV infection from an asymptomatic contact in Germany. $N$ Engl J Med. 2020;382(10):970-971. doi:10.1056/ NEJMc2001468

8. Cheng ZJ, Shan J. Novel coronavirus: where we are and what we know. Infection. 2019;2020(48):155-163. doi:10.1007/s15010020-01401-y

9. Prabakaran P, Xiao X, Dimitrov DS. A model of the ACE2 structure and function as a SARS-CoV receptor. Biochem Biophys Res Commun. 2004;314(1):235-241. doi:10.1016/j. bbrc.2003.12.081

10. Li W, Moore MJ, Vasilieva N, et al. Angiotensin-converting enzyme 2 is a functional receptor for the SARS coronavirus. Nature. 2003;426:450-454. doi:10.1038/nature02145

11. Yan R, Zhang Y, Li Y, Xia L, Guo Y, Zhou Q. Structural basis for the recognition of SARS-CoV-2 by full-length human ACE2. Science. 2020;367:1444-1448. doi:10.1126/science.abb2762

12. Buscarini E, Manfredi G, Brambilla G, et al. GI symptoms as early signs of COVID-19 in hospitalised Italian patients. Gut. 2020;69:1547-1548. doi:10.1136/gutjnl-2020-321434

13. Guan $\mathrm{W}, \mathrm{Ni} \mathrm{Z}, \mathrm{Hu} \mathrm{Y}$, et al. Clinical characteristics of coronavirus disease 2019 in China. N Engl J Med. 2020;382:1708-1720. doi:10.1056/NEJMoa2002032

14. Chen F, Liu ZS, Zhang FR, et al. [First case of severe childhood novel coronavirus pneumonia in China]. Zhonghua Er Ke Za Zhi. 2020;58: E005. doi:10.3760/cma.j.issn.0578-1310.2020.0005. [in Chinese.].

15. Chen N, Zhou M, Dong X, et al. Epidemiological and clinical characteristics of 99 cases of 2019 novel coronavirus pneumonia in Wuhan, China: a descriptive study. Lancet. 2020;395 (10223):507-513. doi:10.1016/S0140-6736(20)30211-7

16. Huang $\mathrm{C}$, Wang $\mathrm{Y}, \mathrm{Li} \mathrm{X}$, et al. Clinical features of patients infected with 2019 novel coronavirus in Wuhan, China. Lancet. 2020;395(10223):497-506. doi:10.1016/S0140-6736(20)30183-5

17. Mehta P, McAuley DF, Brown M, Sanchez E, Tattersall RS, Manson JJ. COVID-19: consider cytokine storm syndromes and immunosuppression. Lancet. 2020;395(10229):1033-1034. doi:10.1016/S0140-6736(20)30628-0

18. Cao W, Liu X, Bai T, et al. High-dose intravenous immunoglobulin as a therapeutic option for deteriorating patients with coronavirus disease 2019. Open Forum Infect Dis. 2020;7(3): ofaa102. doi:10.1093/ofid/ofaa102

19. Wang M, Cao R, Zhang L, et al. Remdesivir and chloroquine effectively inhibit the recently emerged novel coronavirus (2019-nCoV) in vitro. Cell Res. 2020;30(3):269-271. doi:10.1038/s41422-020-0282-0 
20. Chu CM, Cheng VCC, Hung IFN, et al. Role of lopinavir/ritonavir in the treatment of SARS: initial virological and clinical findings. Thorax. 2004;59(3):252. doi:10.1136/thorax.2003.012658

21. Stower H. Lopinavir-ritonavir in severe COVID-19. Nat Med. 2020;26(4):465. doi:10.1038/s41591-020-0849-9

22. Richardson P, Griffin I, Tucker C, et al. Baricitinib as potential treatment for 2019-nCoV acute respiratory disease. Lancet. 2020;395(10223):e30e31. doi:10.1016/S0140-6736(20)30304-4

23. Cantini F, Niccoli L, Matarrese D, Nicastri E, Stobbione P, Goletti D. Baricitinib therapy in COVID-19: a pilot study on safety and clinical impact. $J$ Infect. 2020;81:318-356. doi:10.1016/j.jinf.2020.04.017

24. Lanier LL. Evolutionary struggles between NK cells and viruses. Nat Rev Immunol. 2008;8(4):259-268. doi:10.1038/nri2276

25. Maghazachi AA, Al-Aoukaty A. Chemokines activate natural killer cells through heterotrimeric G-proteins: implications for the treatment of AIDS and cancer. FASEB J. 1998;12 (11):913-924. doi:10.1096/fasebj.12.11.913

26. Jost S, Altfeld M. Control of human viral infections by natural killer cells. Annu Rev Immunol. 2013;31:163-194. doi:10.1146/ annurev-immunol-032712-100001

27. Long EO, Sik Kim H, Liu D, Peterson ME, Rajagopalan S. Controlling natural killer cell responses: integration of signals for activation and inhibition. Annu Rev Immunol. 2013;31:227-258. doi:10.1146/annurev-immunol-020711-075005

28. Cooper MA, Fehniger TA, Turner SC, et al. Human natural killer cells: a unique innate immunoregulatory role for the CD56 ${ }^{\text {bright }}$ subset. Blood. 2001;97(10):3146-3151. doi:10.1182/blood.v97.10.3146

29. Guidotti LG, Chisari FV. Cytokine-mediated control of viral infections. Virology. 2000;273(2):221-227. doi:10.1006/viro.2000. 0442

30. Biron CA, Nguyen KB, Pien GC, Cousens LP, Salazar-Mather TP. Natural killer cells in antiviral defense: function and regulation by innate cytokines. Annu Rev Immunol. 1999;17:189-220. doi:10.1146/annurev.immunol.17.1.189

31. Vivier E, Tomasello E, Baratin M, Walzer T, Ugolini S. Functions of natural killer cells. Nat Immunol. 2008;9(5):503-510. doi:10.1038/ni1582

32. Degli-Esposti MA, Smyth MJ. Close encounters of different kinds: dendritic cells and NK cells take centre stage. Nat Rev Immunol. 2005;5(2):112-124. doi:10.1038/nri1549

33. Cooper MA, Fehniger TA, Caligiuri MA. The biology of human natural killer-cell subsets. Trends Immunol. 2001;22(11):633-640. doi:10.1016/s1471-4906(01)02060-9

34. Maghazachi AA. Compartmentalization of human natural killer cells. Mol Immunol. 2005;42(4):523-529. doi:10.1016/j.molimm.2004 07.036

35. Maghazachi AA. Insights into seven and single transmembrane-spanning domain receptors and their signaling pathways in human natural killer cells. Pharmacol Rev. 2005;57 (3):339-357. doi:10.1124/pr.57.3.5

36. Cantoni $\mathrm{C}$, Bottino $\mathrm{C}$, Vitale $\mathrm{M}$, et al. NKp44, a triggering receptor involved in tumor cell lysis by activated human natural killer cells, is a novel member of the immunoglobulin superfamily. J Exp Med. 1999;189(5):787-796. doi:10.1084/jem.189.5.787

37. Koch J, Steinle A, Watzl C, Mandelboim O. Activating natural cytotoxicity receptors of natural killer cells in cancer and infection. Trends Immunol. 2013;34(4):182-191. doi:10.1016/j.it.2013.01.003

38. Pende D, Parolini S, Pessino A, et al. Identification and molecular characterization of NKp30, a novel triggering receptor involved in natural cytotoxicity mediated by human natural killer cells. $J$ Exp Med. 1999;190(10):1505-1516. doi:10.1084/jem.190.10.1505

39. Pessino A, Sivori S, Bottino C, et al. Molecular cloning of NKp46: a novel member of the immunoglobulin superfamily involved in triggering of natural cytotoxicity. $J$ Exp Med. 1998;188(5):953-960. doi:10.1084/jem.188.5.953
40. Wu J, Song Y, Bakker ABH, et al. An activating immunoreceptor complex formed by NKG2D and DAP10. Science. 1999;285 (5428):730-732. doi:10.1126/science.285.5428.730

41. Hayakawa Y, Huntington ND, Nutt SL, Smyth MJ. Functional subsets of mouse natural killer cells. Immunol Rev. 2006;214:47-55. doi:10.1111/j.1600-065X.2006.00454.x

42. Lanier LL. NK cell receptors. Annu Rev Immunol. 1998;16:359-393. doi:10.1146/annurev.immunol.16.1.359

43. Abel AM, Yang C, Thakar MS, Malarkannan S. Natural killer cells: development, maturation, and clinical utilization. Front Immunol. 2018;9:1869. doi:10.3389/fimmu.2018.01869

44. Sun JC, Lanier LL. NK cell development, homeostasis and function: parallels with CD8+ T cells. Nat Rev Immunol. 2011;11 (10):645-657. doi:10.1038/nri3044

45. Lee S-H, Biron CA. Here today-not gone tomorrow: roles for activating receptors in sustaining NK cells during viral infections. Eur J Immunol. 2010;40(4):923-932. doi:10.1002/eji.201040304

46. Biron CA, Byron KS, Sullivan JL. Severe herpesvirus infections in an adolescent without natural killer cells. $N$ Engl J Med. 1989;320(26):1731-1735. doi:10.1056/NEJM198906293202605

47. Brandstadter JD, Yang Y. Natural killer cell responses to viral infection. J Innate Immun. 2011;3(3):274-279. doi:10.1159/ 000324176

48. Elemam NM, Mekky RY, El-Ekiaby NM, et al. Repressing PU.1 by miR-29a in NK cells of HCV patients, diminishes its cytolytic effect on HCV infected cell models. Hum Immunol. 2015;76 (9):687-694. doi:10.1016/j.humimm.2015.09.021

49. Orange Jordan S. Human natural killer cell deficiencies and susceptibility to infection. Microbes Infect. 2002;4 (15):1545-1558. doi:10.1016/s1286-4579(02)00038-2

50. Yoon JC, Yang CM, Song Y, Lee JM. Natural killer cells in hepatitis C: current progress. World J Gastroenterol. 2016;22 (4):1449-1460. doi:10.3748/wjg.v22.i4.1449

51. Arase H, Lanier LL. Specific recognition of virus-infected cells by paired NK receptors. Rev Med Virol. 2004;14(2):83-93. doi:10.1002/rmv.422

52. Scalzo AA, Yokoyama WM. Cmv1 and natural killer cell responses to murine cytomegalovirus infection. Curr Top Microbiol Immunol. 2008;321:101-122. doi:10.1007/978-3-540-75203-5_5

53. Hammer Q, Rückert T, Romagnani C. Natural killer cell specificity for viral infections. Nat Immunol. 2018;19(8):800-808. doi:10.1038/s41590-018-0163-6

54. Lam VC, Lanier LL. NK cells in host responses to viral infections. Curr Opin Immunol. 2017;44:43-51. doi:10.1016/j. coi.2016.11.003

55. van Erp EA, van Kampen MR, van Kasteren PB, de Wit J. Viral infection of human natural killer cells. Viruses. 2019;11(3):243. doi:10.3390/v11030243

56. Guimei MM, Barqawi HJ, Dash NR, Maghazachi AA. Sepsis-the dilemma continues. MOJ Immunol. 2016;4(3):00125. doi:10.15406/moji.2016.04.00125

57. Liu WJ, Zhao M, Liu K, et al. T-cell immunity of SARS-CoV: implications for vaccine development against MERS-CoV. Antivir Res. 2017;137:82-92. doi:10.1016/j.antiviral.2016.11.006

58. Zhang C, Wang XM, Li SR, et al. NKG2A is a NK cell exhaustion checkpoint for HCV persistence. Nat Commun. 2019;10 (1):1507. doi:10.1038/s41467-019-09212-y

59. Zheng M, Gao Y, Wang G, et al. Functional exhaustion of antiviral lymphocytes in COVID-19 patients. Cell Mol Immunol. 2020;17(5):533-535. doi:10.1038/s41423-020-0402-2

60. Hadjadj J, Yatim N, Barnabei L, et al. Impaired type I interferon activity and inflammatory responses in severe COVID-19 patients. Science. 2020;369(6504):718. doi:10.1126/science.abc6027

61. Cinatl J, Morgenstern B, Bauer G, Chandra P, Rabenau H, Doerr HW. Treatment of SARS with human interferons. Lancet. 2003;362(9380):293-294. doi:10.1016/s0140-6736(03)13973-6 
62. Rothan HA, Byrareddy SN. The epidemiology and pathogenesis of coronavirus disease (COVID-19) outbreak. J Autoimmun. 2020;109:102433. doi:10.1016/j.jaut.2020.102433

63. Wang F, Nie J, Wang $\mathrm{H}$, et al. Characteristics of peripheral lymphocyte subset alteration in COVID-19 pneumonia. $J$ Infect Dis. 2020;221(11):1762-1769. doi:10.1093/infdis/jiaa150

64. Cui W, Fan Y, Wu W, Zhang F, Wang JY, Ni AP. Expression of lymphocytes and lymphocyte subsets in patients with severe acute respiratory syndrome. Clin Infect Dis. 2003;37(6):857-859. doi: $10.1086 / 378587$

65. He Z, Zhao C, Dong Q, et al. Effects of severe acute respiratory syndrome (SARS) coronavirus infection on peripheral blood lymphocytes and their subsets. Int $J$ Infect Dis. 2005;9(6):323-330. doi:10.1016/j.ijid.2004.07.014

66. National Research Project for Sars BG. The involvement of natural killer cells in the pathogenesis of severe acute respiratory syndrome. Am J Clin Pathol. 2004;121(4):507-511. doi:10.1309/ WPK7-Y2XK-NF4C-BF3R.

67. Osman MS, van Eeden C, Cohen Tervaert JW. Fatal COVID-19 infections: is NK cell dysfunction a link with autoimmune HLH? Autoimmun Rev. 2020;19(7):102561. doi:10.1016/j.autrev.2020. 102561

68. Celularity and Infectious Disease Research Institute will try out COVID-19 cell therapy. Available from: https://www.geekwire. com/2020/celularity-infectious-disease-research-institute-winfdas-ok-try-covid-19-cell-therapy. Accessed 2020.

69. Giuliani-promoted COVID-19 therapy from Celularity nabs FDA speedy trial start. Available from: https://www.fiercebiotech.com/ biotech/rudy-giuliani-backed-covid-19-therapy-from-celularitynabs-fda-speedy-trial-start. Accessed 2020.

70. Han J, Chu J, Keung Chan W, et al. CAR-engineered NK cells targeting wild-type EGFR and EGFRvIII enhance killing of glioblastoma and patient-derived glioblastoma stem cells. Sci Rep. 2015;5:11483. doi:10.1038/srep11483

71. Liu E, Marin D, Banerjee P, et al. Use of CAR-transduced natural killer cells in CD19-positive lymphoid tumors. $N$ Engl $\mathrm{J}$ Med. 2020;382(6):545-553. doi:10.1056/NEJMoa1910607

72. Wang W, Jiang J, Wu C. CAR-NK for tumor immunotherapy: clinical transformation and future prospects. Cancer Lett. 2020;472:175-180. doi:10.1016/j.canlet.2019.11.033

73. Market M, Angka L, Martel AB, et al. Flattening the COVID-19 curve with natural killer cell based immunotherapies. Front Immunol. 2020;11:1512. doi:10.3389/fimmu.2020.01512

74. Hachim MY, Elemam NM, Maghazachi AA. The beneficial and debilitating effects of environmental and microbial toxins, drugs, organic solvents and heavy metals on the onset and progression of multiple sclerosis. Toxins. 2019;11(3):147. doi:10.3390/ toxins 11030147

75. Caprariello AV, Rogers JA, Morgan ML, et al. Biochemically altered myelin triggers autoimmune demyelination. Proc Natl Acad Sci USA. 2018;115(21):5528-5533. doi:10.1073/ pnas. 1721115115

76. Steinman L. Multiple sclerosis: a coordinated immunological attack against myelin in the central nervous system. Cell. 1996;85(3):299-302. doi:10.1016/s0092-8674(00)81107-1

77. Maghazachi AA. Role of natural killer cells in multiple sclerosis. ISRN Immunol. 2012;2012:1-14. doi:10.5402/2012/795075

78. Maghazachi AA. On the role of natural killer cells in neurodegenerative diseases. Toxins. 2013;5(2):363-375. doi:10.3390/ toxins 5020363

79. Hestvik AL. The double-edged sword of autoimmunity: lessons from multiple sclerosis. Toxins. 2010;2(4):856-877. doi:10.3390/ toxins 2040856

80. Ghasemi N, Razavi S, Nikzad E. Multiple sclerosis: pathogenesis, symptoms, diagnoses and cell-based therapy. Cell J. 2017;19 (1):1-10. doi:10.22074/cellj.2016.4867
81. Lublin FD, Reingold SC. Defining the clinical course of multiple sclerosis: results of an international survey. National multiple sclerosis society (USA) advisory committee on clinical trials of new agents in multiple sclerosis. Neurology. 1996;46(4):907-911. doi:10.1212/wnl.46.4.907

82. Boiko A, Vorobeychik G, Paty D, Devonshire V, Sadovnick D. Early onset multiple sclerosis: a longitudinal study. Neurology. 2002;59(7):1006-1010. doi:10.1212/wn1.59.7.1006

83. Gadoth N. Multiple sclerosis in children. Brain Dev. 2003;25 (4):229-232. doi:10.1016/s0387-7604(03)00035-4

84. Förster M, Küry $\mathrm{P}$, Aktas $\mathrm{O}$, et al. Managing risks with immune therapies in multiple sclerosis. Drug Saf. 2019;42(5):633-647. doi:10.1007/s40264-018-0782-8

85. Al-Jaderi Z, Maghazachi AA. Utilization of dimethyl fumarate and related molecules for treatment of multiple sclerosis, cancer, and other diseases. Front Immunol. 2016;7:278. doi:10.3389/ fimmu.2016.00278

86. Gandhi R, Laroni A, Weiner HL. Role of the innate immune system in the pathogenesis of multiple sclerosis. $J$ Neuroimmunol. 2010;221(12):7-14. doi:10.1016/j.jneuroim.2009.10.015

87. Lünemann JD, Münz C. Do natural killer cells accelerate or prevent autoimmunity in multiple sclerosis? Brain. 2008;131 (Pt 7)):1681-1683. doi:10.1093/brain/awn132

88. Mimpen M, Smolders J, Hupperts R, Damoiseaux J. Natural killer cells in multiple sclerosis: a review. Immunol Lett. 2020;222:1-11. doi:10.1016/j.imlet.2020.02.012

89. Morandi B, Bramanti P, Bonaccorsi I, et al. Role of natural killer cells in the pathogenesis and progression of multiple sclerosis. Pharmacol Res. 2008;57(1):1-5. doi:10.1016/j.phrs.2007.11.003

90. Leavenworth JW, Schellack C, Kim HJ, Lu L, Spee P, Cantor H. Analysis of the cellular mechanism underlying inhibition of EAE after treatment with anti-NKG2A F(ab')2. Proc Natl Acad Sci USA. 2010;107(6):2562-2567. doi:10.1073/pnas.0914732107

91. Hao J, Liu R, Piao W, et al. Central nervous system (CNS)resident natural killer cells suppress Th17 responses and CNS autoimmune pathology. J Exp Med. 2010;207(9):1907-1921. doi:10.1084/jem.20092749

92. Matsumoto Y, Kohyama K, Aikawa Y, et al. Role of natural killer cells and TCR $\gamma \delta$ T cells in acute autoimmune encephalomyelitis. Eur J Immunol. 1998;28(5):1681-1688. doi:10.1002/(SICI)15214141(199805)28:05<1681::AID-IMMU1681>3.0.CO;2-T

93. Segal BM. The role of natural killer cells in curbing neuroinflammation. $J$ Neuroimmunol. 2007;191(12):2-7. doi:10.1016/j.jneuroim.2007.09.006

94. Takahashi K, Aranami T, Endoh M, Miyake S, Yamamura T. The regulatory role of natural killer cells in multiple sclerosis. Brain. 2004;127(Pt 9):1917-1927. doi:10.1093/brain/awh219

95. Liu Q, Sanai N, Jin WN, La-Cava A, Van-Kaer L, Shi FD. Neural stem cells sustain natural killer cells that dictate recovery from brain inflammation. Nat Neurosci. 2016;19(2):243-252. doi: $10.1038 / \mathrm{nn} .4211$

96. Lepennetier G, Hracsko Z, Unger M, et al. Cytokine and immune cell profiling in the cerebrospinal fluid of patients with neuro-inflammatory diseases. J Neuroinflammation. 2019;16 (1):219. doi:10.1186/s12974-019-1601-6

97. Gross CC, Schulte-Mecklenbeck A, Rünzi A, et al. Impaired NK-mediated regulation of T-cell activity in multiple sclerosis is reconstituted by IL-2 receptor modulation. Proc Natl Acad Sci USA. 2016;113(21):E2973E2982. doi:10.1073/pnas.1524924113

98. Rodríguez-Martín E, Picón C, Costa-Frossard L, et al. Natural killer cell subsets in cerebrospinal fluid of patients with multiple sclerosis. Clin Exp Immunol. 2015;180(2):243-249. doi:10.1111/ cei. 12580

99. Pandya AD, Al-Jaderi Z, Høglund RA, et al. Identification of human NK17/NK1 cells. PLoS One. 2011;6(10):e26780. doi:10.1371/journal.pone. 0026780 
100. Elemam NM, Hannawi S, Maghazachi AA. Innate lymphoid cells (ILCs) as mediators of inflammation, release of cytokines and lytic molecules. Toxins. 2017;9(12):E398. doi:10.3390/ toxins 9120398

101. Gross CC, Schulte-Mecklenbeck A, Wiendl H, et al. Regulatory functions of natural killer cells in multiple sclerosis. Front Immunol. 2016;7:606. doi:10.3389/fimmu.2016.00606

102. Durrenberger PF, Webb LV, Sim MJ, et al. Expression in white matter lesions in multiple sclerosis. Immunology. 2012;137 (4):317-325. doi:10.1111/imm. 12012

103. Laroni A, Uccelli A. CD56bright natural killer cells: a possible biomarker of different treatments in multiple sclerosis. J Clin Med. 2020;9:5. doi:10.3390/jcm9051450

104. Arnon R, Aharoni R. Mechanism of action of glatiramer acetate in multiple sclerosis and its potential for the development of new applications. Proc Natl Acad Sci USA. 2004;101:14593-14598. doi:10.1073/pnas.0404887101

105. Kala M, Miravalle A, Vollmer T. Recent insights into the mechanism of action of glatiramer acetate. J Neuroimmunol. 2011;235 (12):9-17. doi:10.1016/j.jneuroim.2011.01.009

106. Weber MS, Starck M, Wagenpfeil S, Meinl E, Hohlfeld R, Farina C. Multiple sclerosis: glatiramer acetate inhibits monocyte reactivity in vitro and in vivo. Brain. 2004;127(Pt 6):1370-1378. doi:10.1093/brain/awh163

107. Sand KL, Knudsen E, Rolin J, Al-Falahi Y, Maghazachi AA. Modulation of natural killer cell cytotoxicity and cytokine release by the drug glatiramer acetate. Cell Mol Life Sci. 2009;66 (8):1446-1456. doi:10.1007/s00018-009-8726-1

108. Høglund RA, Holmøy T, Harbo HF, Maghazachi AA. A one year follow-up study of natural killer and dendritic cells activities in multiple sclerosis patients receiving glatiramer acetate (GA) PLoS One. 2013;8(4):e62237. doi:10.1371/journal.pone.0062237

109. Duda PW, Schmied MC, Cook SL, Krieger JI, Hafler DA Glatiramer acetate $\left(\right.$ Copaxone $\left.{ }^{\circledR}\right)$ induces degenerate, Th2polarized immune responses in patients with multiple sclerosis. J Clin Invest. 2000;105(7):967-976. doi:10.1172/JCI8970

110. Kim HJ, Ifergan I, Antel JP, et al. Type 2 monocyte and microglia differentiation mediated by glatiramer acetate therapy in patients with multiple sclerosis. J Immunol. 2004;172(11):7144-7153. doi:10.4049/jimmunol.172.11.7144

111. Moharregh-Khiabani D, Linker RA, Gold R, Stangel M. Fumaric acid and its esters: an emerging treatment for multiple sclerosis. Curr Neuropharmacol. 2009;7(1):60-64. doi:10.2174/ 157015909787602788

112. Bomprezzi R. Dimethyl fumarate in the treatment of relapsing-remitting multiple sclerosis: an overview. Ther $A d v$ Neurol Disord. 2015;8(1):20-30. doi:10.1177/1756285614564152

113. Linker RA, Lee DH, Ryan S, et al. Fumaric acid esters exert neuroprotective effects in neuroinflammation via activation of the Nrf2 antioxidant pathway. Brain. 2011;134(Pt 3)):678-692. doi:10.1093/brain/awq386

114. Marastoni D, Buriani A, Pisani AI, et al. Increased NK cell count in multiple sclerosis patients treated with dimethyl fumarate: a 2-year longitudinal study. Front Immunol. 2019;10:1666. doi:10.3389/fimmu.2019.01666

115. de Jong R, Bezemer AC, Zomerdijk TP, van de Pouw-kraan T, Ottenhoff TH, Nibbering PH. Selective stimulation of T helper 2 cytokine responses by the anti-psoriasis agent monomethylfumarate. Eur J Immunol. 1996;26(9):2067-2074. doi:10.1002/eji.1830260916

116. Al-Jaderi Z, Maghazachi AA. Vitamin $\mathrm{D}_{3}$ and monomethyl fumarate enhance natural killer cell lysis of dendritic cells and ameliorate the clinical score in mice suffering from experimental autoimmune encephalomyelitis. Toxins. 2015;7(11):4730-4744. doi: $10.3390 /$ toxins 7114730
117. Elemam NM, Al-Jaderi Z, Hachim MY, Maghazachi AA. HCT116 colorectal cancer cells secrete chemokines which induce chemoattraction and intracellular calcium mobilization in NK92 cells. Cancer Immunol Immunother. 2019;68(6):883-895. doi:10.1007/s00262-019-02319-7

118. Vego H, Sand KL, Høglund RA, et al. Monomethyl fumarate augments NK cell lysis of tumor cells through degranulation and the upregulation of NKp46 and CD107a. Cell Mol Immunol. 2016;13(1):57-64. doi:10.1038/cmi.2014.114

119. Maghazachi AA, Sand KL, Al-Jaderi Z. Glatiramer acetate, dimethyl fumarate, and monomethyl fumarate upregulate the expression of CCR10 on the surface of natural killer cells and enhance their chemotaxis and cytotoxicity. Front Immunol. 2016;7:437. doi:10.3389/fimmu.2016.00437

120. Mohan T, Deng L, Wang BZ. CCL28 chemokine: an anchoring point bridging innate and adaptive immunity. Int Immunopharmacol. 2017;51:165-170. doi:10.1016/j. intimp.2017.08.012

121. Muhammad JS, Jayakumar MN, Elemam NM, et al. Gasdermin D hypermethylation inhibits pyroptosis and LPS-induced IL-1 $\beta$ release from NK92 cells. Immunotargets Ther. 2019;8:29-41. doi:10.2147/ITT.S219867

122. Smith MD, Calabresi PA, Bhargava P. Dimethyl fumarate treatment alters NK cell function in multiple sclerosis. Eur J Immunol. 2018;48(2):380-383. doi:10.1002/eji.201747277

123. Medina S, Villarrubia N, Sainz de la Maza S, et al. Optimal response to dimethyl fumarate associates in MS with a shift from an inflammatory to a tolerogenic blood cell profile. Mult Scler. 2018;24(10):1317-1327. doi:10.1177/1352458517717088

124. Ascherio A, Munger KL. Environmental risk factors for multiple sclerosis. Part II: noninfectious factors. Ann Neurol. 2007;61 (6):504-513. doi:10.1002/ana.21141

125. Lemire JM, Archer DC. 1,25-dihydroxyvitamin $\mathrm{D}_{3}$ prevents the in vivo induction of murine experimental autoimmune encephalomyelitis. $J$ Clin Invest. 1991;87(3):1103-1107. doi: $10.1172 /$ JCI115072

126. Cantorna MT, Hayes CE, DeLuca HF. 1,25-Dihydroxyvitamin $\mathrm{D}_{3}$ reversibly blocks the progression of relapsing encephalomyelitis, a model of multiple sclerosis. Proc Natl Acad Sci USA. 1996;93 (15):7861-7864. doi:10.1073/pnas.93.15.7861

127. Burton JM, Kimball S, Vieth R, et al. A Phase I/II dose-escalation trial of vitamin D3 and calcium in multiple sclerosis. Neurology. 2010;74(23):1852-1859. doi:10.1212/WNL.0b013e3181e1cec2

128. Hupperts R, Smolders J, Vieth R, et al. Randomized trial of daily high-dose vitamin $\mathrm{D}(3)$ in patients with RRMS receiving subcutaneous interferon $\beta$-1a. Neurology. 2019;93(20):e1906e1916. doi:10.1212/wnl.0000000000008445

129. Rinaldi AO, Sanseverino I, Purificato C, et al. Increased circulating levels of vitamin D binding protein in MS patients. Toxins. 2015;7(1):129-137. doi:10.3390/toxins7010129

130. Al-Jaderi Z, Maghazachi AA. Effects of vitamin D3, calcipotriol and FTY720 on the expression of surface molecules and cytolytic activities of human natural killer cells and dendritic cells. Toxins. 2013;5(11):1932-1947. doi:10.3390/toxins5111932

131. Smolders J, Peelen E, Thewissen M, et al. Safety and T cell modulating effects of high dose vitamin $\mathrm{d} 3$ supplementation in multiple sclerosis. PLoS One. 2010;5(12):e15235. doi:10.1371/ journal.pone. 0015235

132. Smolders J, Thewissen M, Peelen E, et al. Vitamin D status is positively correlated with regulatory $\mathrm{T}$ cell function in patients with multiple sclerosis. PLoS One. 2009;4(8):e6635. doi:10.1371/ journal.pone.0006635

133. Connor P, Comi G, Montalban X, et al. Oral fingolimod (FTY720) in multiple sclerosis: two-year results of a Phase II extension study. Neurology. 2009;72(1):73-79. doi:10.1212/01. wnl.0000338569.32367.3d 
134. Kappos L, Antel J, Comi G, et al. Oral fingolimod (FTY720) for relapsing multiple sclerosis. $N$ Engl $J$ Med. 2006;355 (11):1124-1140. doi:10.1056/NEJMoa052643

135. Rolin J, Sand KL, Knudsen E, Maghazachi AA. FTY720 and SEW2871 reverse the inhibitory effect of S1P on natural killer cell mediated lysis of K562 tumor cells and dendritic cells but not on cytokine release. Cancer Immunol Immunother. 2010;59 (4):575-586. doi:10.1007/s00262-009-0775-7

136. Saraste M, Irjala H, Airas L. Expansion of CD56bright natural killer cells in the peripheral blood of multiple sclerosis patients treated with interferon-beta. Neurol Sci. 2007;28(3):121-126. doi:10.1007/s10072-007-0803-3
137. Martínez-Rodríguez JE, López-Botet M, Munteis E, et al. Natural killer cell phenotype and clinical response to interferon-beta therapy in multiple sclerosis. Clin Immunol. 2011;141(3):348-356. doi:10.1016/j.clim.2011.09.006

138. Kaufmann M, Haase R, Proschmann U, Ziemssen T, Akgün K. Real-world lab data in natalizumab treated multiple sclerosis patients up to 6 years long-term follow up. Front Neurol. 2018;9:1071. doi:10.3389/fneur.2018.01071

139. Greenfield AL, Hauser SL. B-cell therapy for multiple sclerosis: entering an era. Ann Neurol. 2018;83(1):13-26. doi:10.1002/ ana.25119

\section{Publish your work in this journal}

Infection and Drug Resistance is an international, peer-reviewed openaccess journal that focuses on the optimal treatment of infection (bacterial, fungal and viral) and the development and institution of preventive strategies to minimize the development and spread of resistance. The journal is specifically concerned with the epidemiology of antibiotic resistance and the mechanisms of resistance development and diffusion in both hospitals and the community. The manuscript management system is completely online and includes a very quick and fair peerreview system, which is all easy to use. Visit http://www.dovepress.com/ testimonials.php to read real quotes from published authors. 